\title{
Two Fatal Cases of Hepatitis B Virus Carriers after Corticosteroid Therapy for Bronchial Asthma
}

\author{
Yuriko Koga, Ryukichi Kumashiro, Kiyoshi Yasumoto, Satoshi Shakado, Noriyuki Ono, \\ Hideya Noguchi, Kazuyoshi Nagata, Michio Sata, Hirohiko Abe, Nobuo KaKu* and Kyuichi Tanikawa
}

We report two hepatitis B virus (HBV) carriers who had liver failure after withdrawal of corticosteroids (steroids) administered for treatment of serious asthmatic attacks. Liver functions deteriorated 1 to 2 wk after withdrawal of the steroid therapy and liver failure occurred. Steroid readministration and intensive therapy for liver failure did not prevent death. An excessive immune response provoked by steroid withdrawal and decreased reserve capacity due to underlying chronic liver disease were thought to be factors in the liver failure. Caution must be exercised in the administration of steroids to patients with underlying chronic $\mathrm{HBV}$ infection to prevent exacerbation of hepatitis. Prompt readministration of steroids is indicated if evidence of liver failure develops.

(Internal Medicine 31: 208-213, 1992)

Key words: type B chronic hepatitis, acute liver failure, fulminant hepatitis

\section{Introduction}

Corticosteroids (steroids) are used commonly in clinical medicine, and there are many instances in which hepatitis $\mathrm{B}$ virus (HBV) infected patients are given steroids for the treatment of various diseases. Steroids have an immunosuppressive effect, however withdrawal is followed by an immune rebound. Utilizing this effect, steroids, in a tapering manner, have been administered to those with a hepatitis $\mathrm{B}$ e antigen $(\mathrm{HBe} \mathrm{Ag}$ )-positive state to achieve a seroconversion to antibody to the $\mathrm{HBeAg}$ (anti $\mathrm{HBe}$ )-positive state. This steroid withdrawal therapy is, however, followed by a transient exacerbation of liver function. When steroids are tapered off, recovery of the immune response may cause reactivation of cytotoxic $T$ cells which leads to hepatocyte destruction and elevation of serum transaminases in HBV carrier patients. We report two cases of HBV carriers who developed fatal liver failure after steroid therapy for complicated asthmatic attacks.

\section{Case Reports}

Case 1 (Fig. 1)

A 53-year-old woman was admitted to a local hospital because of asthmatic attacks on January 21, 1989. She received intravenous (iv) hydrocortisone $(300 \mathrm{mg} /$ day) for 26 days from January 21 to February 15 , and a dose of $200 \mathrm{mg} /$ day for 7 days from February 16 to February 22 , in addition to the use of bronchial dilators and antibiotics. Laboratory data on February 27, five days after the last administration of steroid, showed slightly elevated serum levels of total bilirubin (T.B) to $2.4 \mathrm{mg} / \mathrm{dl}$ and glutamate-oxaloacetate transaminase (GOT) to $67 \mathrm{KU}$. Jaundice was progressive, and ascites and a bleeding tendency developed on March 15. On March 20 , her liver begun to fail, her level of consciousness decreased, and prothrombin time (PT) was $28 \%$ of control. The patient had no history of liver disease, nor alcohol or tobacco use. She was transferred to the Critical Care Center of Kurume University Hospital on March 26. On admission, her level of consciousness was grade II on the hepatic coma scale, she was jaundiced, and she had gingival bleeding. The liver and spleen were not palpable, but tenderness of the epigastrium, right hypochondrium, and liver to palpation were noted. She also was noted to have pretibial edema.

Laboratory findings on admission are shown in Table 1. Complete blood count (CBC) showed that the white blood cell count (WBC) was elevated to $13,400 / \mathrm{mm}^{3}$.

From The Second Department of Medicine and *Critical Care Centcr, Kurume University School of Medicine, Kurume

Received for publication January 11, 1991; Accepted for publication June 6, 1991

Reprint requests should be addressed to Yuriko Koga, The Second Department of Medicine, Kurume University School of Medicine, 67 Asahimachi, Kurume 830, Japan 


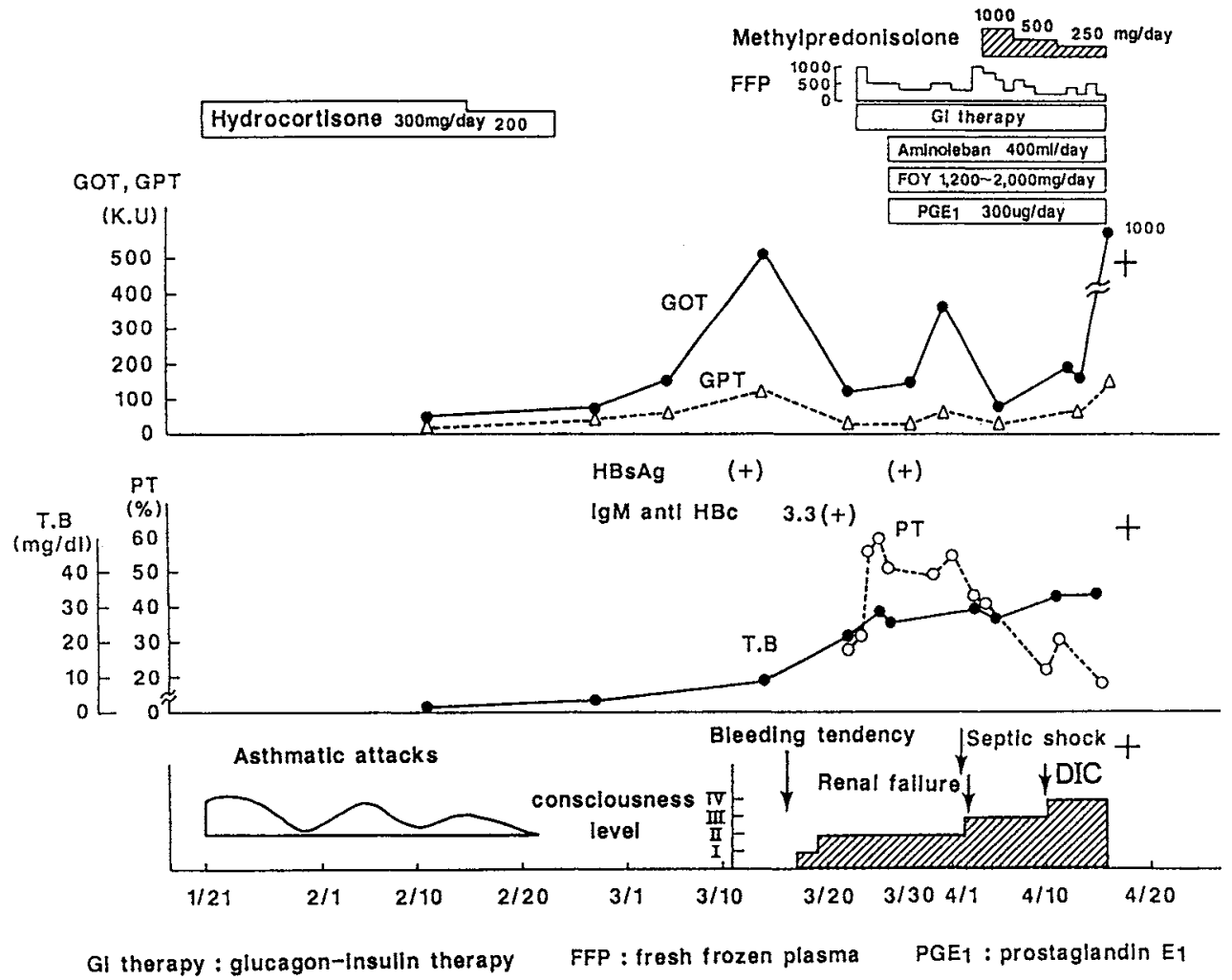

Fig. 1. Clinical course (Case 1)

Table 1. Laboratory Data on Admission (Case 1)

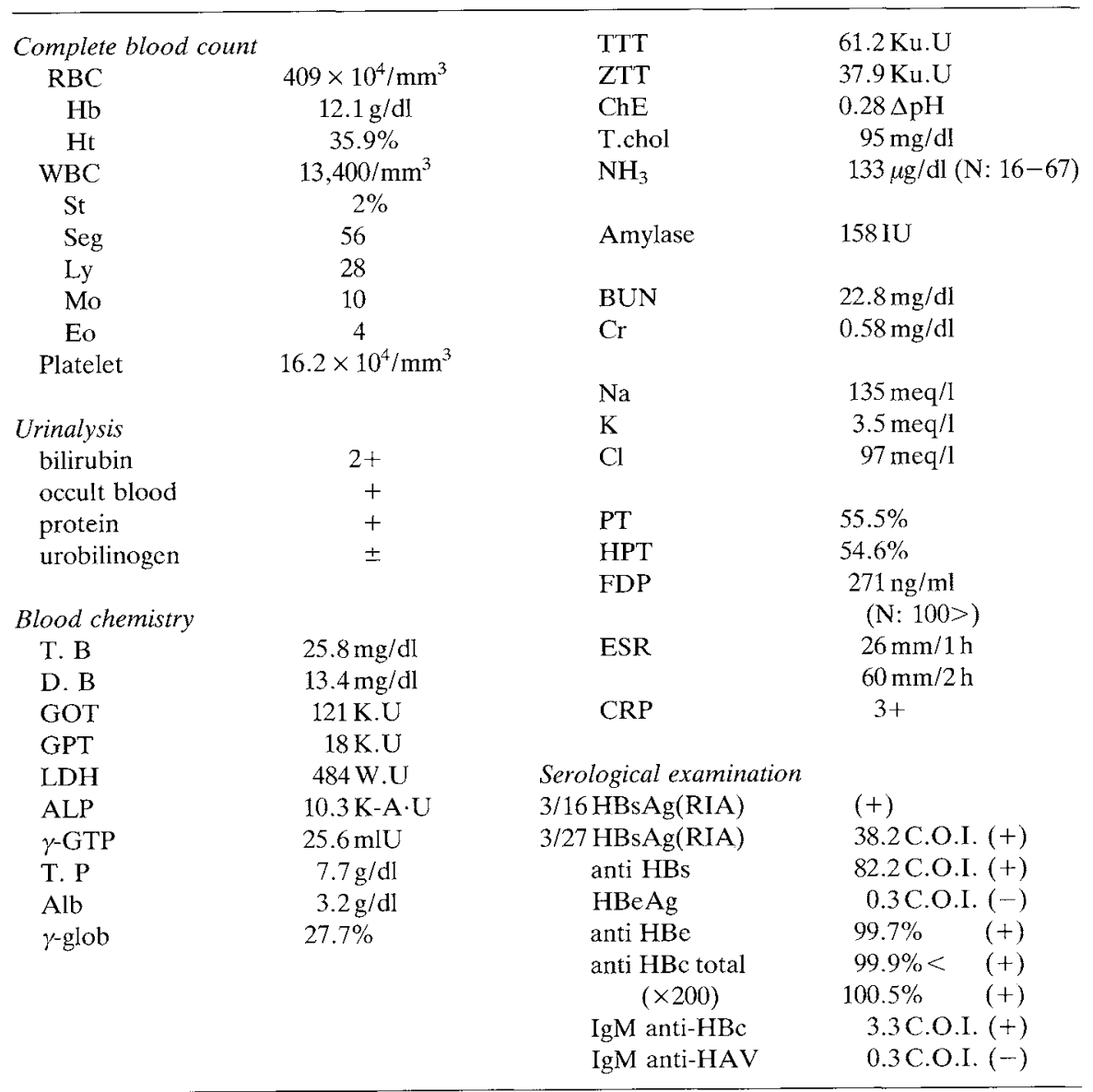


Urinalysis was positive for bilirubin, occult blood and protein. Blood chemistry revealed a serum T.B of $25.8 \mathrm{mg} / \mathrm{dl}$, and the venous ammonia level $\left(\mathrm{NH}_{3}\right)$ was increased to $133 \mu \mathrm{g} / \mathrm{dl}$. PT and hepaplastin test (HPT) became worse at $55.5 \%$ and $54.6 \%$, respectively. Fibrin/ fibrinogen degradation products (FDP) was increased to $271 \mu \mathrm{g} / \mathrm{ml}$. Serologic examination was positive for hepatitis B surface antigen (HBsAg) and a high total antibody to hepatitis $\mathrm{B}$ core antigen $($ anti- $\mathrm{HBc}$ ) titer indicated that the patient was a $\mathrm{HBV}$ carrier. $\mathrm{IgM}$ anti-HBc was positive at 3.3C.O.I., $\mathrm{HBeAg}$ was negative and anti-HBe was positive. The HBsAg subtype was $a d r$. DNA-polymerase (DNA-p) was positive at $66 \mathrm{cpm}$. IgM antibody to hepatitis A virus (IgM anti-HAV), antibody to hepatitis C virus (anti-HCV) and antibody to hepatitis D virus (anti HDV) were all negative.

Glucagon-insulin infusion therapy (GI) and administration of fresh frozen plasma (FFP) which had been started in the previous hospital were continued. Administration of branched chain amino acid solution (BCAA) was started for control of the hepatic encephalopathy and gabexat-emesilate (GM) was used for the disseminated intra-vascular coagulation (DIC) indicated by the FDP elevation. Prostaglandin $\mathrm{E}_{1}\left(\mathrm{PGE}_{1}\right)$ was added for hepatocyte protection. The liver failure was thought to have been caused by reactivation of an immune response as a result of discontinuation of the steroid for the asthmatic attacks, and readministration of steroid was begun. This intensive therapy was not effective and the patient developed septic shock and acute renal failure, and died from multiple organ failure on April 15, 52 days after cessation of the steroid on February 22, 1989.

An autopsy was authorized. Liver weight was $1,540 \mathrm{~g}$ and the histological findings of the liver were as follows. Submassive necrosis was observed with remarkable bile plugging. Conspicuous fibrosis was seen in zone 3 and reticular fibrosis was observed in the portal area and between zones 1 and 3. P-P and P-C bridging was observed (Figs. 2, 3).

\section{Case 2 (Fig. 4)}

A 68-year-old man was admitted to a local hospital for asthma and pneumonia on August 20,1988. He had an asthmatic attack on February 28, 1989, and received intravenous hydrocortisone at $500 \mathrm{mg} /$ day for 5 days from March 4 to March 8 and $100 \mathrm{mg} /$ day for 3 days from March 9 to March 11, in addition to the use of bronchial dilators and antibiotics. He reported poor appetite and generalized fatigue late in March. On April 8 hematemesis developed, and on April 10 blood chemistry revealed marked liver dysfunction. He became unconscious on April 11 and was tranferred to our hospital on the following day. He had been diagnosed as a HBV carrier at the age of 40 , and was being followed for chronic hepatitis. His two children were also HBV carriers. He previously had used alcohol and tobacco, but stopped

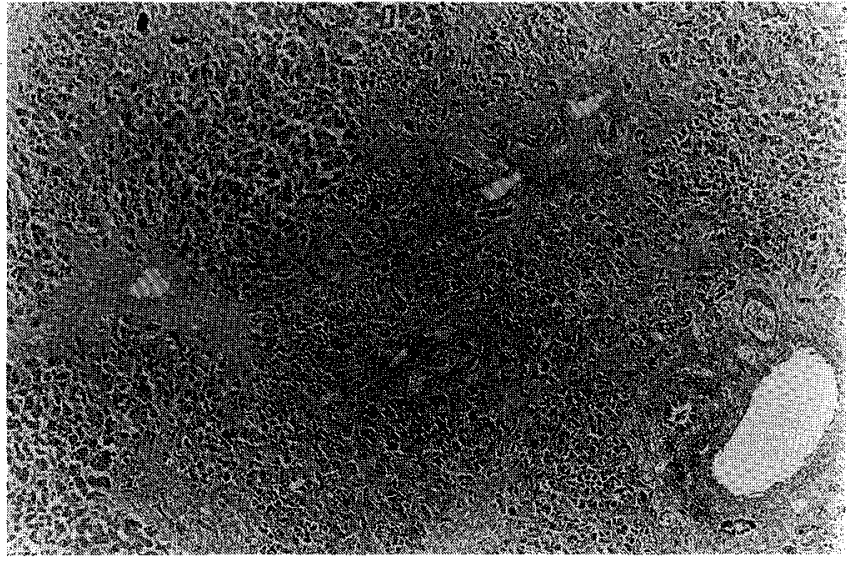

Fig. 2. Hepatic light microscopic findings (Case 1). Submassive necrosis is obscrved and bile plugging is remarkable (HE stain, $\times 33$ ).

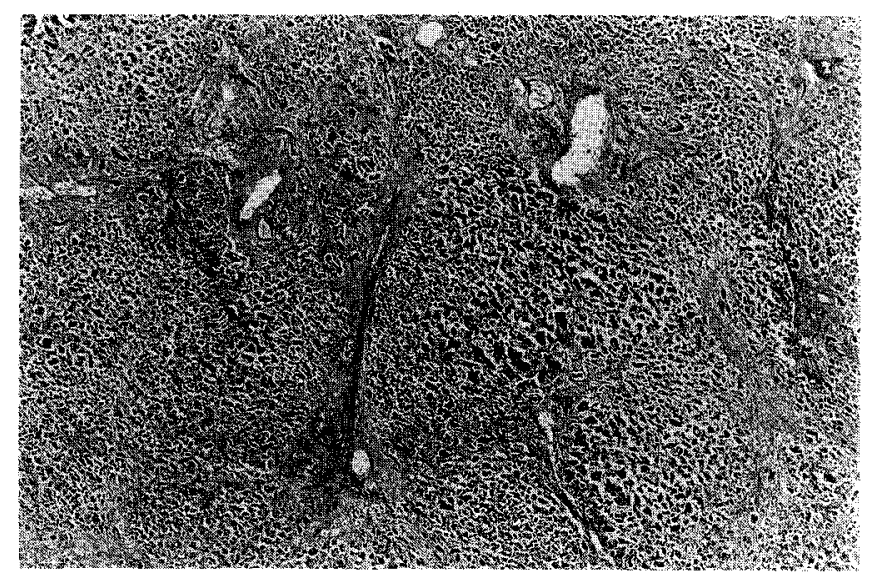

Fig. 3. Hepatic light microscopic findings (Case 1). Conspicuous fibrosis is seen in zone 3. Reticular fibrosis is observed in the portal area and between zone 1 and zone 3. A tendency for P-P and P-C bridging is observed (Mallory Azan stain, $\times 25$ ).

use of both in August 1988. On admission his level of consciousness was grade IV on the hepatic coma scale and he was severely jaundiced. Wheezing was heard throughout the lung fields. The liver and spleen were not palpable, and there was no ascites.

Laboratory findings on admission are shown in Table 2. CBC showed that the WBC was elevated at 19,400 / $\mathrm{mm}^{3}$. Urinalysis was positive for bilirubin and occult blood. Blood chemistry analyses revealed a serum T.B of $17.1 \mathrm{mg} / \mathrm{dl}$, serum GOT of $705 \mathrm{KU}$, serum glutamatepyruvate transaminase (GPT) OF $1154 \mathrm{KU}$, thymol turbidity test (TTT) of $20.0 \mathrm{KuU}$, zinc surfate turbidity test (ZTT) of $18.7 \mathrm{KuU}$, and that the serum albumin (Alb) had decreased to $2.5 \mathrm{~g} / \mathrm{dl}$ and cholinesterase (ChE) to $0.16 \Delta \mathrm{pH}$. The venous ammonia level $\left(\mathrm{NH}_{3}\right)$ was increased to $268 \mu \mathrm{g} / \mathrm{dl}$. PT was $10 \%$ of control and HPT was less than $10 \%$. FDP had increased to $557 \mu \mathrm{g} / \mathrm{ml}$. The patient was diagnosed as a HBV carrier by serologic examination, namely a positive HBsAg and a high total anti- $\mathrm{HBc}$ titer. $\mathrm{IgM}$ anti-HBc was positive at 1.0 C.O.I., $\mathrm{HBeAg}$ was negative and anti-HBe was 


\section{Liver Failure after Steroid Therapy}

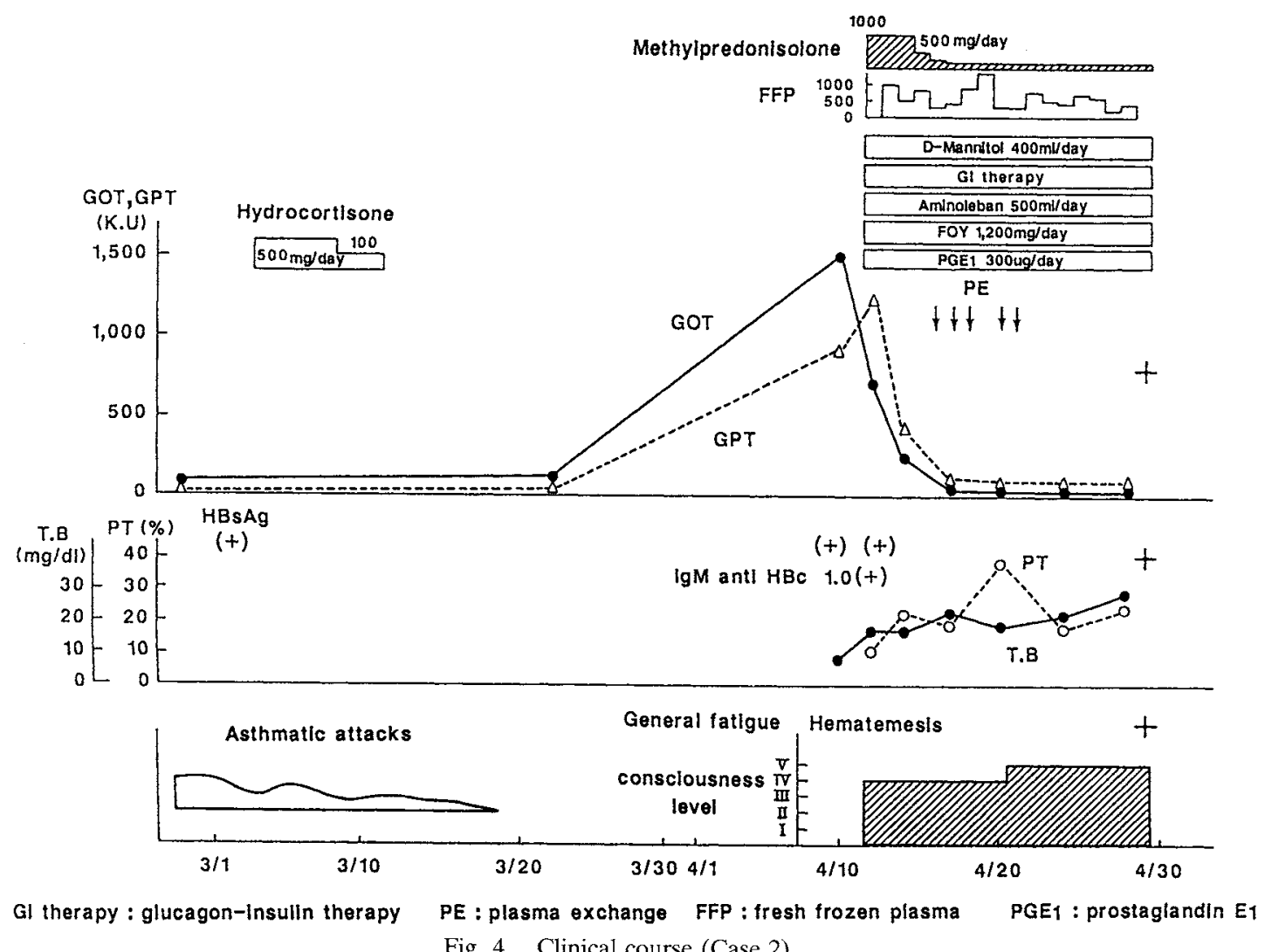

Table 2. Laboratory Data on Admission (Case 2)

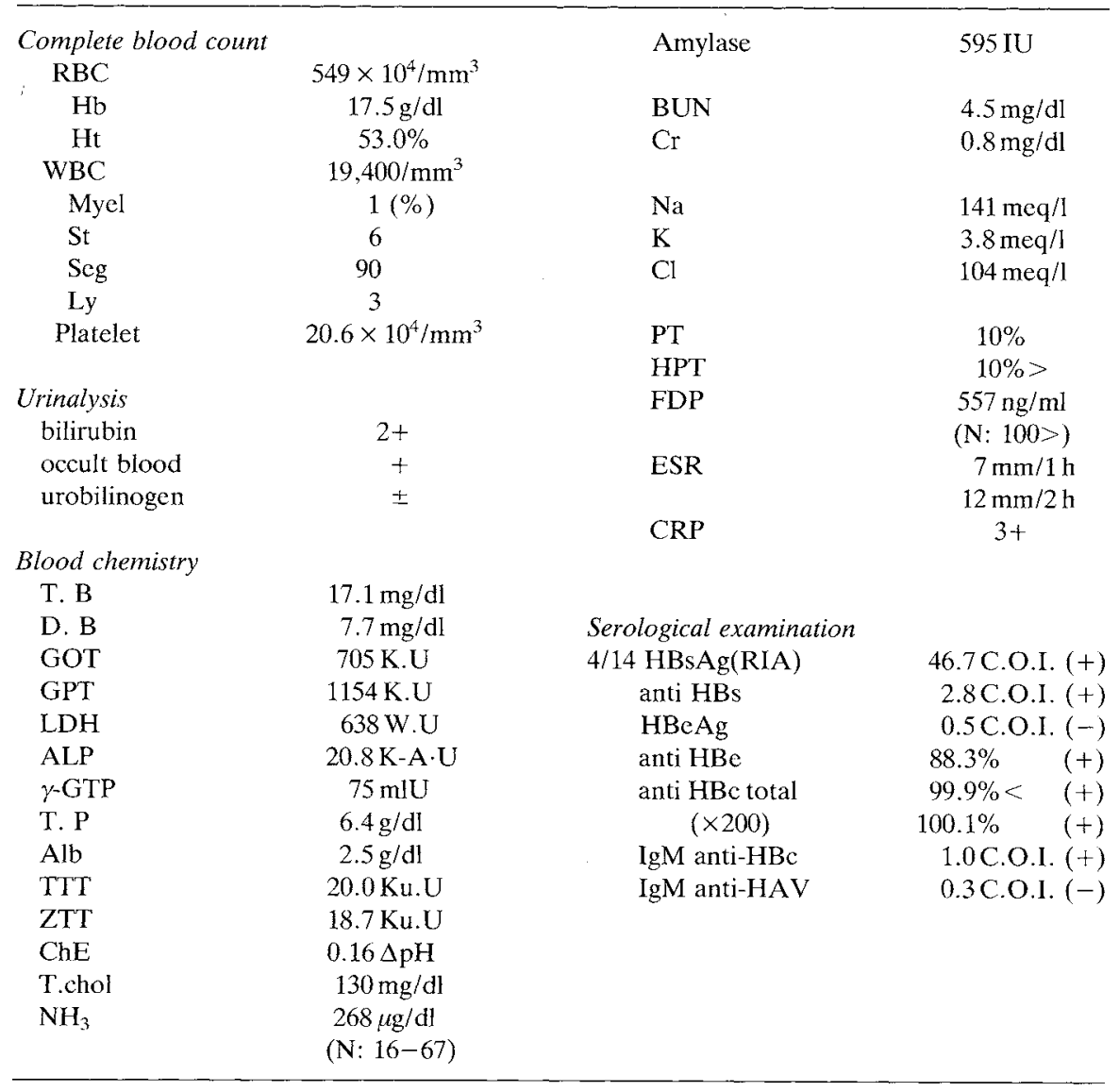


positive. The HBsAg subtype was $a d r$. DNA-p was negative at $25 \mathrm{cpm}$. IgM anti-HAV, anti-HCV and antiHDV were all negative.

Liver failure was thought to be caused by discontinuation of the steroid used for the asthmatic attacks, and readministration of steroid was immediately begun. GI, BCAA, GM, mannitol, $\mathrm{PGE}_{1}$ and plasma exchange were all used for the management of various complications, including hepatic coma, cerebral edema, and DIC. The serum transaminase levels rapidly decreased, but the level of consciousness did not improve and he died of multiple organ failure on April 29, 39 days after discontinuation of the steroid on March 11.

An autopsy was authorized. The liver weighed $550 \mathrm{~g}$ and histological examination revealed submassive necrosis and remarkable bile duct proliferation. A mass of residual hepatocytes resembling a regenerative nodule was seen, and fibrosis was seen around a mass of residual hepatocytes and proliferative bile ducts (Figs. 5, 6).

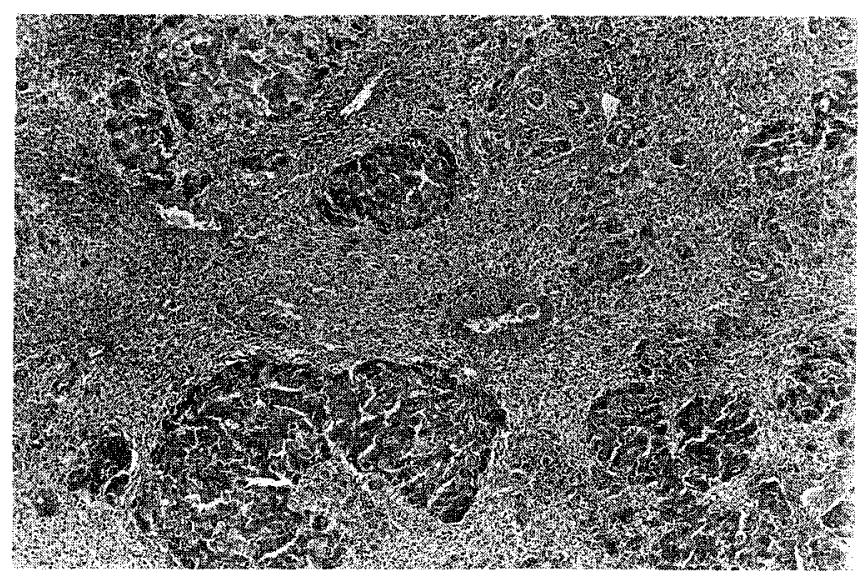

Fig. 5. Hepatic light microscopic findings (Case 2). Submassive necrosis is observed with remarkable bile duct proliferation. A mass of residual hepatocytes resembling a regenerative nodule is seen (HE stain, $\times 33$ ).

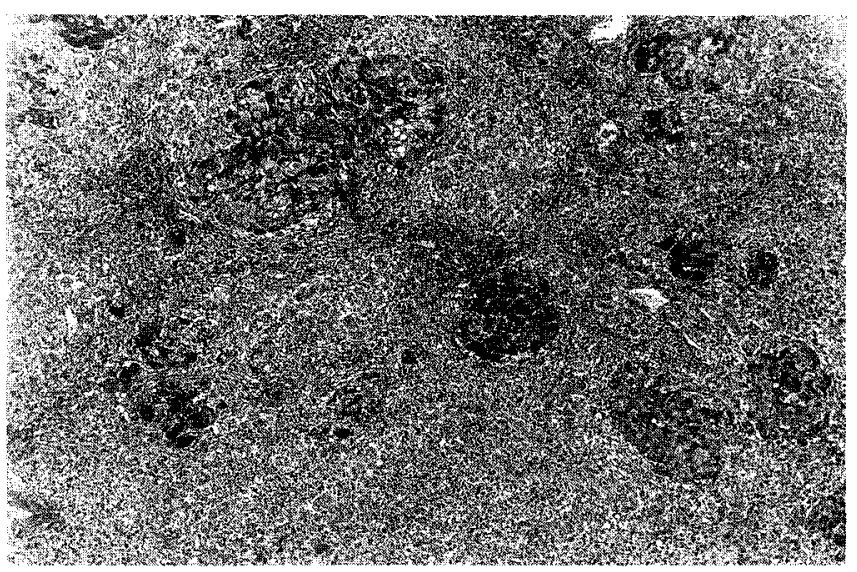

Fig. 6. Hepatic light microscopic findings (Case 2). Fibrosis is seen surrounding a mass of residual hepatocytes and proliferative bile ducts (Mallory Azan stain, $\times 33$ ).

\section{Discussion}

It is well known that steroid withdrawal therapy, one of the therapies for type B chronic hepatitis, is useful to deplete HBeAg through the immune modulating effect of the corticosteroid (1). Steroid administration brings about a decreased immune response to $\mathrm{HBV}$ and the number of hepatocytes infected by HBV increases during this therapy. Steroid dose reduction or discontinuation brings about recovery of the immune response to $\mathrm{HBV}$, especially that of cytotoxic T cells, and HBV infected hepatocytes are destroyed. The purpose of this therapy is to destroy all HBV infected hepatocytes and thereby exclude HBV from the liver. However, the hepatocyte destruction often leads to liver failure if an excessive immune response occurs or if the hepatic reserve capacity is small due to underlying chronic liver disease. In fact, it has been reported that steroid withdrawal therapy for $\mathrm{HBV}$ carriers can lead to severe liver damage in some cases $(2,3)$.

Steroids are commonly used in various fields of clinical medicine, and there are many situations in which HBV carrier patients are given steroids as therapy for complicated diseases. Steroids may be effective for those complicated diseases, but the acute and drastic immune reactivation in the liver caused by withdrawal of the therapy may lead to liver failure primarily through increased cell mediated cytotoxicity. It has been reported that $\mathrm{HBV}$ carrier patients treated with steroids for malignancies, nephrotic syndrome, and arthritis develope fatal liver failure (4-6). Of the two patients reported here, case 1 had no prior history of liver disease and was diagnosed as a HBV carrier for the first time during the present admission. She was given steroids for asthmatic attacks, her liver function worsened 5 days after the last administration, and she died 7 wk later. Case 2 was being followed for type $\mathrm{B}$ chronic hepatitis. He was given steroid for asthmatic attacks, as in case 1 , he developed generalized fatigue and poor appetite $2 \mathrm{wk}$ after the last administration, and he died 5 wk later. Superimposed HAV, HDV, and HCV infection were excluded by serologic examinations. No history of blood transfusion or excessive alcohol intake were identified. Liver function abnormalities were noted 1 to $2 \mathrm{wk}$ after the last steroid administration, $\operatorname{IgM}$ anti- $\mathrm{HBc}$ was positive in both patients, and DNA polymerase was positive in one case. Postulating the cause of their liver failure based on the clinical course and serological findings described above, we believed that the steroid administered for the asthmatic attacks had led to an increase in the HBV and discontinuation of the steroids was followed by acute and drastic hepatocyte destruction secondary to an excessive immune response.

The severity of liver disease was not known prior to steroid administration in either case, but postmortem histological examination suggested chronic liver disease, 
and it is possible that the hepatic reserve capacities were decreased to some extent. Therefore, a decrease in hepatic reserve capacity was thought to be one of the factors involved in the liver failure in these cases.

It has been reported that some patients with type $B$ chronic hepatitis, in spite of being positive for anti $\mathrm{HBe}$, exhibit fluctuating serum transaminase and DNA-p levels, as well as exacerbations of liver function and have died due to liver failure (7-9). In 1989, Carman et al showed a mutation in the genome base arrangement in the precore region which controls the secretion of $\mathrm{HBeAg}$ outside the hepatocytes. This mutation is thought to prevent hepatocytes from secreting $\mathrm{HBeAg}$ which then increases within the hepatocytes (10). Exacerbations of type B chronic hepatitis are thought to be caused not only by an immune activation, but also by changes in the nature of the infectious agents resulting from gene mutation, thereby providing a new immune target for cytotoxic $\mathrm{T}$ cells. HBV precore mutant genes have been detected in many patients with fulminant hepatitis (11). It is possible that the activation of a HBV mutation was one of the causes of the liver failure in the present cases.

Tanaka et al (6) reported 3 cases of HBV carriers who developed liver failure following steroid therapy for other diseases. Two of these cases were post $\mathrm{HBeAg}$ seroconversion and anti-HBe was positive before steroid administration; the third case was post seroconversion at the onset. Although $\mathrm{HBeAg}$ and anti-HBe were not measured in either of the present two cases before admission, they were thought to be post $\mathrm{HBeAg}$ seroconversion based on the results obtained after admission. It may be that an immune reaction or antibody production more readily occurs in those who are anti-HBe positive than in those who are $\mathrm{HBeAg}$ positive. The present two cases suggest that proliferation of $\mathrm{HBV}$ in hepatocytes can be induced by steroid administration even in the anti-HBe positive state.

Steroids are useful drugs, but if they are given to $\mathrm{HBV}$ carriers, an exacerbation of hepatitis can occur, therefore it is critical to be aware of any exacerbation of hepatitis or signs of liver failure. Readministration of steroids is reported to be effective in patients with hepatitis exacerbated by steroid withdrawal therapy $(2,3)$. In the present cases, the time of readministration of steroids was thought to be too late to avoid liver failure. If there are signs of exacerbation, such as elevation of serum transaminases or prolongation of the prothrombin time, it is necessary to increase the dose of steroid or to immediately readminister steroids before liver failure occurs. And careful tapering of the steroid dosage is also an important prophylaxis against acute exacerbation of chronic liver disease.

Acknowledgment: We are grateful to Ms. Fumiko Fukuda for preparation of the manuscript.

\section{References}

1) Kumada $\mathrm{H}$, Yoshiba A, Oyake $\mathrm{E}$, et al. Study of the seroconversion from e-Ag to e-Ab by corticosteroid treatment in the HBs positive chronic hepatitis. Acta Hepatol Jpn 22: 803, 1981.

2) Shimizu $M$, Adachi $N$, Tokita $H$, et al. A case of chronic active hepatitis type $\mathbf{B}$ with severe liver dysfunction induced by steroid withdrawal therapy-Improved by remedication of corticosteroid. Acta Hepatol Jpn 26: $921,1985$.

3) Arase $Y$, Kumada $H$, Ikeda $K$, et al. Three cases of chronic liver disease with severe liver dysfunction after corticosteroid withdrawal therapy. Acta Hepatol Jpn 28: 600, 1987.

4) Galbraith RM, Eddleston ALWF, Williams R, et al. Fulminant hepatic failure in leukemia and choriocarcinoma related to withdrawal of cytotoxic drug therapy. Lancet 20: 528, 1975.

5) Thung SN, Gerber MA, Klion F, et al. Massive hepatic necrosis after chemotherapy withdrawal in a hepatitis $B$ virus carrier. Arch Int Med 145: 1313, 1985.

6) Tanaka $H$, Yasunaga $M$, Shirasawa $H$, et al. Three cases of HBsAg carrier with fulminant liver failure induced by withdrawal of steroid therapy. Acta Hcpatol Jpn 29: 1509, 1988.

7) Akahane $\mathrm{Y}$, Kiyosawa $\mathrm{K}$, Nagata $\mathrm{A}$, et al. Studies on $\mathrm{HBeAg}$ / anti-HBe in $\mathrm{HBsAg}$ positive liver disease and asymptomatic HBsAg carriers (AsC) Part 2: Clinical significance of $\mathrm{HBeAg} /$ anti-HBe in HBsAg positive diseases. Acta Hepatol Jpn 21: 391, 1980.

8) Nishihara $T$, Yamada $G$, Mizuno $M$, et al. Clinical studies on the cases of anti-HBe-positive chronic hepatitis with acute exacerbation. Acta Hcpatol Jpn 23: 1133, 1982.

9) Miura M, Nakamura M, Nakano $Y$, et al. A case of anti-HBe positive chronic hepatitis type $B$ with evolution of fulminant hepatitis-like fatal course due to HBV-reactivation. Acta Hepatol Jpn 26: 1522, 1985.

10) Carman WF, Jacyna MR, Hadziyannis $S$, et al. Mutation preventing formation of hepatitis $\mathrm{B} e$ antigen in patients with chronic hepatitis B infection. Lancet 9: 588, 1990.

11) Kosaka Y, Takase K, Kojima M, et al. Fulminant hepatitis B: Induction by hepatitis $B$ virus mutants defective in the precore region and incapable of cncoding e antigen. Gastroenterology 100: 1087, 1991. 